Research Article

\title{
Experimental Investigations on Pullout Behavior of HDPE Geogrid under Static and Dynamic Loading
}

\author{
Zheng Zuo $\mathbb{D}^{1},{ }^{1}$ Guangqing Yang $\mathbb{D}^{2,3}$ He Wang, ${ }^{2}$ and Zhijie Wang ${ }^{2}$ \\ ${ }^{1}$ School of Traffic and Transportation, Shijiazhuang Tiedao University, Shijiazhuang, Hebei 050043, China \\ ${ }^{2}$ School of Civil Engineering, Shijiazhuang Tiedao University, Shijiazhuang, Hebei 050043, China \\ ${ }^{3}$ Key Laboratory of Traffic Safety and Control in Hebei, Shijiazhuang 050043, China \\ Correspondence should be addressed to Guangqing Yang; yanggq@stdu.edu.cn
}

Received 1 June 2020; Accepted 4 September 2020; Published 23 October 2020

Academic Editor: Antonio Boccaccio

Copyright ( $\odot 2020$ Zheng Zuo et al. This is an open access article distributed under the Creative Commons Attribution License, which permits unrestricted use, distribution, and reproduction in any medium, provided the original work is properly cited.

This paper describes a series of laboratory pullout tests that were performed to investigate the pullout behavior of high-density polyethylene (HDPE) uniaxial geogrid subjected to static and dynamic loading. Pullout tests were conducted on HDPE geogrid reinforced coarse sand under normal static loading (60-300 kPa), dynamic loading with different amplitudes (20, 40, and 60 kPa), and different frequencies $(2,4$, and $6 \mathrm{~Hz})$ by using the newly developed pullout apparatus. The results indicated that the pullout resistance of geogrid presented different growth patterns with the increase of normal loads under static loading. The amplitude and frequency both had significant effects on the interaction between reinforcement and soil, and the increment of the pullout resistance was $0.6 \mathrm{kN}$ and $0.3 \mathrm{kN}$, respectively. The effect of dynamic loading on the soil-geogrid interface can be gradually equivalent to that of static loading corresponding to the balance position of dynamic loading with the increase of frequency compared with the static loading. The results of this study are helpful for the selection of the strength of the reinforcement in different locations and to simplify the study on the stress of reinforcement in reinforced soil structures under traffic loads.

\section{Introduction}

In recent decades, geosynthetic-reinforced soil (GRS) structures have been constructed more frequently, such as subgrade $[1,2]$, embankment $[3,4]$, retaining walls $[5-7]$, slopes $[8,9]$, and landfills $[10,11]$, because they have the advantages of low cost [12], simple construction, and environmental protection $[8,13]$ and can deform without damage. High-density polyethylene (HDPE) geogrids, as an example of the important geosynthetics reinforcement materials, are commonly adopted in many GRS structures, such as reinforced soil retaining wall and reinforced slopes, especially for steep slopes [14-16], because of their excellent mechanical characteristics such as high strength, high elongation, and durability. In addition, the geogrid can significantly enhance the bearing capacity and reduce the settlement [17-19]. To give full play to the performance advantages of the geogrid, extensive investigations have been conducted on the performance of the geogrid reinforced soil structure by several authors [20,21].

The deformation conditions and the engineering performance of the soil are a significant improvement by the friction of the interface of reinforced soil. Hence, the friction characteristics $[22,23]$ of the interface between soil and geogrid reinforcement are one of the important factors to be considered in the design and stability analysis of GRS structures. The pullout test [24-26] is an effective and also commonly used method to investigate the interaction of the interface between soil and reinforcement. In order to simulate the interaction process and further understand the mechanical behavior and deformation characteristics of geogrid reinforcement, many laboratory experiments have been performed by several authors [27-29]. At the same time, some valuable results were obtained by a series of pullout tests.

Abdi and Mirzaeifar [26] conducted pullout tests to investigate the effect of the particle size and distribution on 
the friction characteristics of the soil-geogrid interface. It was observed that the pullout resistance increased with the increase of the particle size and nonuniformity, and the particle size had a greater influence. Altay et al. [30] studied the interaction of the interface between geogrid and clay soil. In addition, the effect of the moisture content of the clay soil on the pullout resistance was also examined. The test results showed that when the moisture content of clay was the optimum moisture content (OMC), the pullout resistance was the largest. Wang et al. [31] conducted laboratory pullout tests and numerical simulations to investigate the effect of the number of transverse members on the pullout resistance. By visualizing the interaction of geogrid and soil in the numerical model, the load transfer characteristics were also analysed. Peng and Zornberg [32] used transparent soil to visualize the interaction of the soil-geogrid interface to study the mechanism of loads transfer. Cardile et al. [33] investigated the effect of the interference mechanism between two transverse ribs on the bearing capacity based on laboratory pullout tests and proposed a theoretical method to predict the peck pullout resistance.

The above-mentioned literature mainly studied the influence of the properties of the infill materials and reinforcements on the friction characteristics of the soil-geogrid interface through pullout tests. In addition, the normal static loading is also one of the important factors that affect the mechanical behavior of the interface. The interaction of the soil-geogrid interface was investigated under static loading $(\sigma=20,40$, and $100 \mathrm{kPa})$ by Wang et al. [31]. Aali et al. [34] studied the influence of the number of longitudinal and transverse rib members on the pullout force by conducting a series of pullout tests under normal static loading $(\sigma=20,40$, and $80 \mathrm{kPa}$ ). The pullout characteristics of waste tire strips with uniaxial and biaxial geogrids were conducted under $\sigma=20,40,50$, and $60 \mathrm{kPa}$ by Li et al. [35]. In the present study, there is a lack of detailed investigations into the variations of the pullout capacity of geogrid reinforcement under higher normal static loading as compared to past studies.

In addition to static loading, GRS structures are generally subjected to dynamic loading [36]. At present, deformation calculation and stability analysis of reinforced soil retaining walls are generally based on the friction strength parameters between soil and reinforcement under static loading. Traditional testing methods where the friction coefficient of the interface between soil and reinforcement was obtained by static loading may be adopted, but these are limited to light traffic loads and slow speed. However, reinforced soil structures are generally subjected to dynamic loading generated from earthquakes and traffic loads. Specifically, the effect of traffic loading on the reinforced soil structures cannot be ignored. Hence, the effect of dynamic loading on the interface friction strength of reinforced soil and the change of interface strength after dynamic loading are need further research.

Cardile et al. [37] studied the effect of cyclic loading history (effective stress $=10,25,50$, and $100 \mathrm{kPa} ; f=1 \mathrm{~Hz}$ ) on the pullout resistance and the stability of the interface. The test results indicated that the mechanical behavior of the soil-geogrid interface was related to the amplitude of the cyclic loading and effective stress. Liu et al. [38] tested the tensile strain of geogrid under different amplitudes and frequencies and obtained the dynamic characteristics and cumulative deformation development law of retaining wall under repeated traffic load. Hussaini et al. [39] investigated the mechanical behavior of the ballast-geogrid interface under cyclic loading. It was observed that the geogrid can effectively prevent the lateral movement of ballast and reduce the settlement. However, the failure of larger particles was relatively high. In contrast to the above-mentioned studies, the effect of the dynamic loading with higher loading amplitude and higher frequency on the strength of the interface lacked enough research. Meanwhile, the relationship of the strength of the interface between static loading and dynamic loading also lacked enough research. To further understand the pullout behavior and deformation characteristics of geogrid reinforcement, a large-scale laboratory pullout apparatus was developed. The newly developed equipment provides the basis for research.

In this paper, a series of laboratory pullout tests were performed on HDPE uniaxial geogrid by using the newly developed pullout apparatus under static and dynamic loading. The effects of several factors, including the value of the normal static loading and the frequency and amplitude of dynamic loading, on the pullout resistance were investigated. Additionally, the relationship of the pullout behavior of the geogrid subjected to static and dynamic loading was also discussed.

\section{Laboratory Pullout Apparatus}

In this paper, a large-scale multifunction laboratory pullout apparatus, which can be applied to both static loading and dynamic loading, was developed to examine the friction characteristics of the interface between soil and geogrid reinforcement under different loading scenarios. The newly developed pullout apparatus is mainly comprised of four components: a rigid steel pullout box, normal loading system, horizontal control system, and a data acquisition system. Table 1 presents the main technical parameters of the pullout apparatus, and the view of the apparatus is shown in Figure 1.

2.1. Pullout Box. Several factors, including the types and sizes of geosynthetics and the shape and size of infill materials, were considered to design the dimensions of the pullout box. The inner dimensions of the pullout box developed in this study were $600 \mathrm{~mm} \times 400 \mathrm{~mm} \times 500 \mathrm{~mm}$ $(L \times W \times H)$, and the material is a steel plate with the thickness of $15 \mathrm{~mm}$. What is more, the reinforced ribs, namely, steel transverse ribs, were uniformly arranged around the box to protect the sides of the test box from deformation and even damage during the pullout test, as shown in Figure 1.

In the traditional apparatus, the front displacement monitored by the displacement sensors at the clamp is generally adopted to analyse and discuss the results of the 
TABle 1: Main technical parameters of static and dynamic pullout apparatus.

\begin{tabular}{|c|c|c|c|c|c|c|c|}
\hline \multicolumn{3}{|c|}{ Test box inner dimensions } & \multirow[b]{2}{*}{$\begin{array}{l}\text { Pullout rate } \\
(\mathrm{mm} / \mathrm{min})\end{array}$} & \multirow[b]{2}{*}{$\begin{array}{l}\text { Pullout horizontal displacement } \\
\qquad(\mathrm{mm})\end{array}$} & \multicolumn{2}{|c|}{ Maximum loads } & \multirow[b]{2}{*}{$\begin{array}{l}\text { Frequency } \\
\quad(\mathrm{Hz})\end{array}$} \\
\hline $\begin{array}{l}\begin{array}{l}\text { Length } \\
(\mathrm{mm})\end{array} \\
\end{array}$ & $\begin{array}{l}\text { Width } \\
(\mathrm{mm})\end{array}$ & $\begin{array}{c}\text { Height } \\
(\mathrm{mm})\end{array}$ & & & $\begin{array}{c}\text { Normal } \\
(\mathrm{kPa})\end{array}$ & $\begin{array}{l}\text { Horizontal } \\
(\mathrm{kN})\end{array}$ & \\
\hline 600 & 400 & 500 & $0 \sim 30$ & 150 & 800 & 100 & $0 \sim 30$ \\
\hline
\end{tabular}

pullout test. Additionally, the calculation formula of the shear stress was $\tau=T / 2 L B$, where $T$ was pullout resistance at the moment when geogrid was pulled out; $L$ and $B$ were the length and width of the reinforcement placed on the inside of the pullout box, respectively. It should be noted that, for the duration of the test of the traditional apparatus, the contact area of the interface between reinforcement and soil decreased with an increase in the relative displacement of the soil-geogrid interface, which will cause the results obtained from the laboratory pullout tests to be greater than the real values. Therefore, the newly developed apparatus needs to solve this problem.

A slot was set on both the front and back of the box, one of which is close to the clamp and the other is far away from the clamp as shown in Figures 1 and 2. Firstly, the height of the slot is consistent with the height of the clamp to ensure that the reinforcement was pulled out in a horizontal state during the test. In addition, taking into account the types of geosynthetics and the thickness of reinforcement, the height of the narrow gap can be adjusted to meet the requirements of different tests and reinforcements. Last but most important, the setting of the back slot is aimed at keeping the contact area of the soil-geogrid interface constant for the duration of the test. Due to the existence of the back slot, the geogrid can be placed along the longitudinal direction of the test box, and the end of the geogrid reinforcement can extend to the outside of the test box. The back slot is designed to ensure the accuracy of the calculation results of the formula. What is more, the end of the reinforcement is connected to the back displacement (BD) sensor by a clean steel wire rope to monitor the relative displacement of soilgeogrid during the test.

Compared with other test apparatus, the newly developed pullout box had a larger internal size, and the test box was made from steel, so the quality will be greater after filling. To ensure that the test can be carried out smoothly and quickly, the pullout box was equipped with some auxiliary facilities. Multiple linear guide rails were arranged under the test platform. The setting of the linear guide rail is helpful for not only the movement of the test box but also the loading and unloading of the infill materials. Additionally, a limit device was set to ensure that the test box located directly under the loading plate to avoid the friction between the loading plate and the inner wall of the pullout box. To prevent the infill material from falling into the linear guide rail through the narrow gap in front of the pullout box during the test, the baffle was added to the test platform.

2.2. Normal Loading System. In the design of this equipment, the inverted hydraulic loading method was adopted through the action of the reaction frame. The hydraulic pump applied the normal loading to the infill material in the pullout box through the loading plate. To avoid the friction between the pressure plate and the side wall of the pullout box during the test, the size of the loading plate made from steel was $590 \mathrm{~mm}$ in length, $390 \mathrm{~mm}$ in width, and $35 \mathrm{~mm}$ in thickness. A series of tests, including strength and stiffness tests, were carried out on the loading plate to avoid producing deflection and even damage when transferring the normal loading. The tests showed that, in the process of the test, no deformation was found on the loading plate under the normal loading up to $1000 \mathrm{kPa}$. The maximum normal loading applied to the apparatus is $800 \mathrm{kPa}$. The frequency of the dynamic loading was up to $50 \mathrm{~Hz}$. At the same time, several waves, including sine wave, triangle wave, square wave, and combination wave, can be applied by the normal loading system. The normal loading system can apply not only static loading but also dynamic loading. Additionally, an important function of the normal loading system was to meet the relative density of the infill material in the experimental programs by using the loading plate.

\subsection{Horizontal Control System. The horizontal servo control} system adopted the strain control type. The improvement feature of the pullout apparatus was the pullout rate and the horizontal displacement, because limited researches had been conducted on the effect of the pullout rate on the friction characteristic of the soil-geogrid interface. The increase of the horizontal displacement can greatly reduce the size effect of the geogrid specimen and provide the basis for the subsequent study of the effect of the number and the position of the transverse ribs on the interaction mechanism. The clamp with complementary concave convex and a sine wave can ensure that the tested geosynthetic sample does not slide and reduce the damage to the geosynthetic sample. The force sensor and displacement sensor were set at the clamp, which were connected with the computer. The time interval of data acquisition was set at the computer terminal so as to accurately record the pullout resistance and the pullout displacement during the test.

2.4. Data Acquisition and Processing System. To facilitate the setting and input of test parameters in the process of the test, the pullout apparatus was equipped with data acquisition and processing system, which can not only monitor but also record some important data. It is important for the apparatus to monitor the normal loading during the test because it needed to ensure that the normal load applied to the infill material was constant and stable, especially for high static loading and dynamic loading. In addition, the pullout resistance, the front and back displacement monitored by sensors, and the curve of the data can be obtained from the 


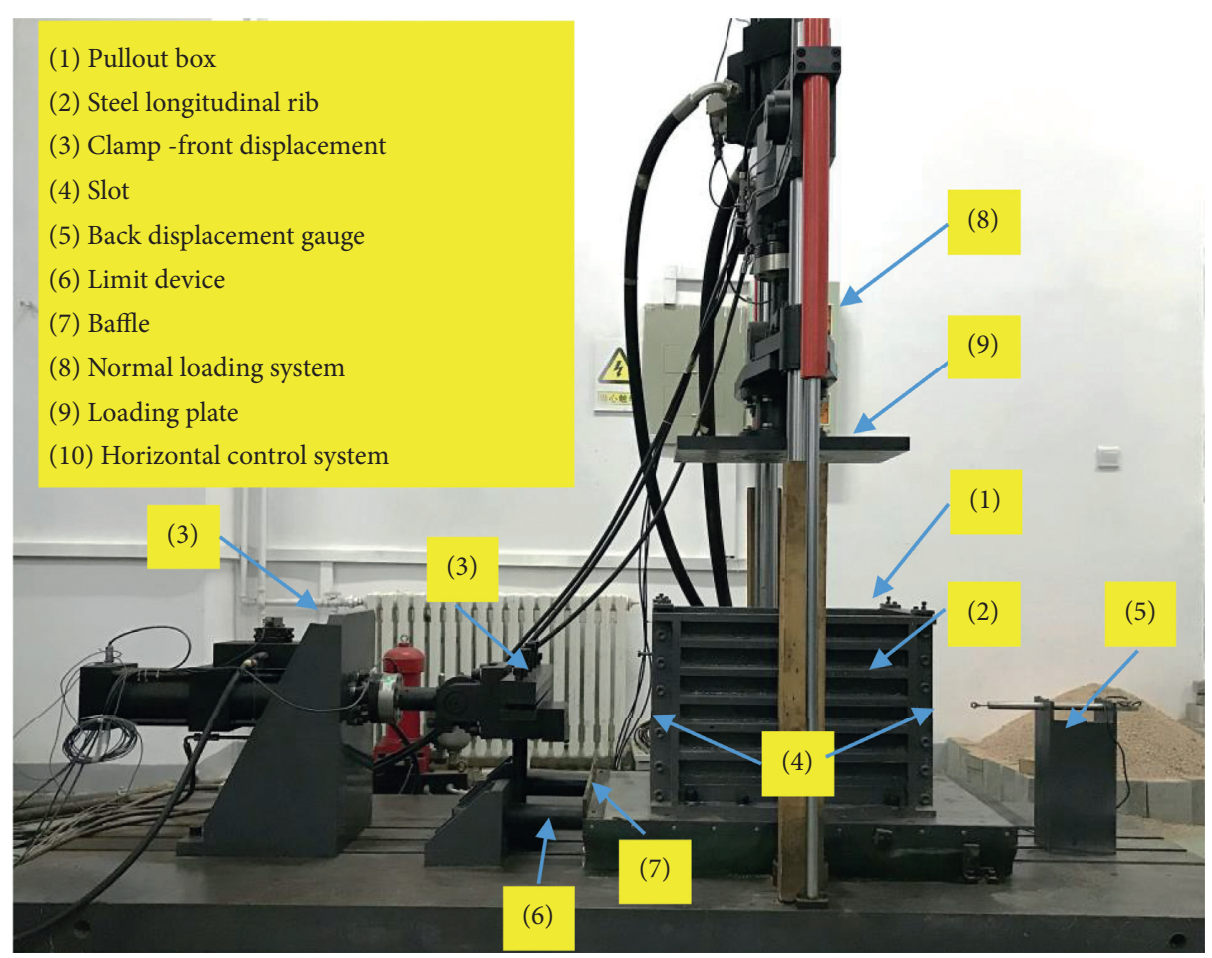

Figure 1: The view of the pullout apparatus.

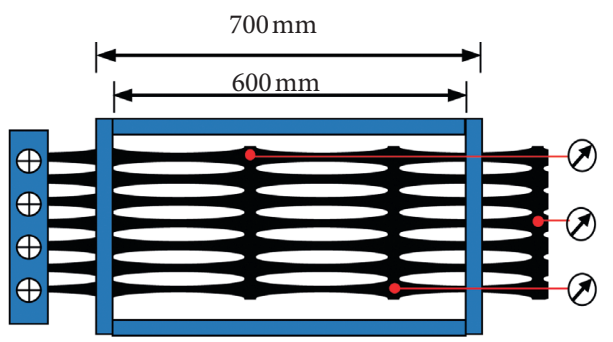

(a)

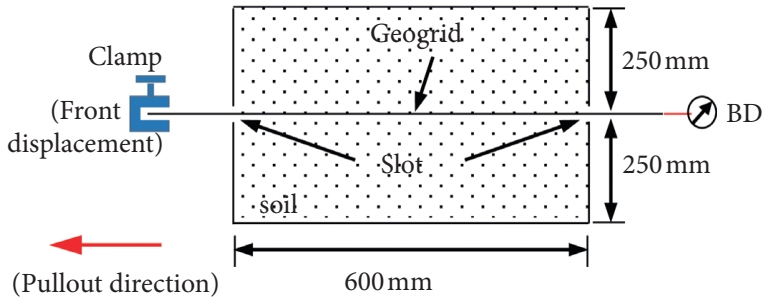

(b)

Figure 2: The view of slot and displacement meter of the pullout apparatus.

data acquisition system to enhance the control of the test progress. Last, in order to ensure the safety of the experimenters during the test, the special protection devices, which included force protection and displacement protection, were set in the software system.

\subsection{Summary of Pullout Apparatus Characteristics.} Compared with the previous apparatus, the developed pullout apparatus had the following technical characteristics:

(1) The normal loading can apply a high normal static load of up to $800 \mathrm{kPa}$ to simulate the vertical pressure of reinforced buildings such as high slope and high retaining wall. At the same time, different parameters such as waveform, load amplitude, frequency, and cycle times can be set to simulate the dynamic load.

(2) The overall rigidity of the test box is improved significantly by the reinforced ribs uniformly arranged around the side of the box, providing a guarantee for the pullout test under high normal static loading and dynamic loading.

(3) The setting of the slot at the front and back can not only ensure that the contact area between the reinforcement and the filler is constant but also measure the real pullout displacement between the reinforcement and the infill material.

(4) The data acquisition system improves the accuracy of the data and strengthens the control of the test process.

\section{Test Materials and Experimental Program}

3.1. InFill Material. The infill material used in this study was coarse sand with a particle size distribution varying from 0.1 to $10 \mathrm{~mm}$. The particle size distribution curve of the coarse sand determined from sieve analysis is shown in Figure 3. Coarse sand can be classified as well-graded sand (SW) 


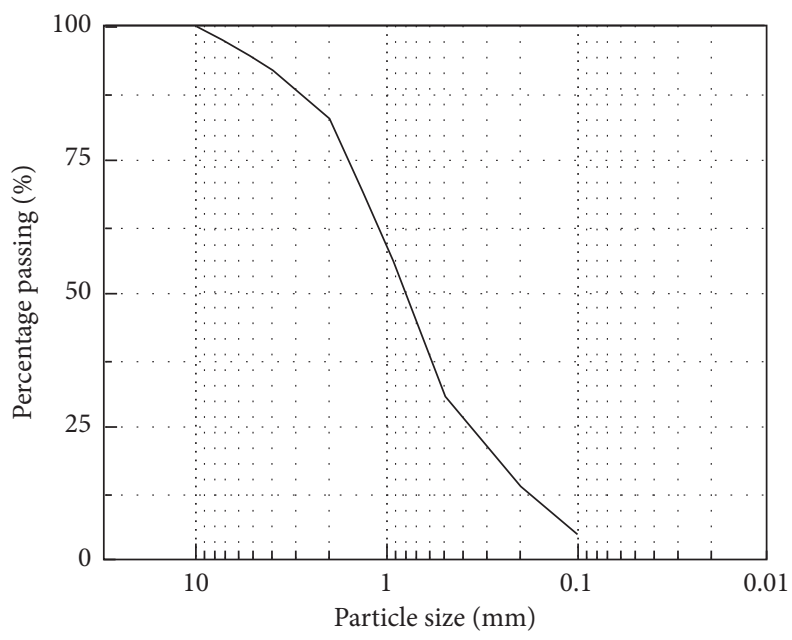

FIGURe 3: Particle size distribution curve of the coarse sand.

according to the Unified Soil Classification System (USCS) (ASTM D2487-11).

To determine the shear strength parameters of the infill material used in the test, a series of laboratory direct shear tests (DST) were performed. It should be noted that the selection of the normal loads in the direct shear test (DST) should be consistent with the pullout test to ensure that the effect of the load on the particles was excluded. DST was carried out on specimens with dimensions of $20 \mathrm{~mm}$ in height and $61.8 \mathrm{~mm}$ in inner diameter under three normal stresses of $80 \mathrm{kPa}, 100 \mathrm{kPa}$, and $120 \mathrm{kPa}$. The basic physical properties of the coarse sand are summarized in Table 2. The dimension of above and below the reinforcement inside the newly developed pullout apparatus meets the requirements of ASTM D6706: soil thickness greater than $150 \mathrm{~mm}$, six times 85\%-passing particle size (D85) of sand material, and three times the maximum particle size $\left(D_{\max }\right)$ of the soil used in testing.

3.2. Reinforcement Material. The reinforcement material used in this study was uniaxial geogrid, which was made from stretched high-density polyethylene (HDPE). The engineering properties of the geogrid used in this study are presented in Table 3.

3.3. Experimental Programs. Experimental programs are mainly comprised of two components: static loading and dynamic loading. The reinforcements are generally subjected to gravity loads from Earth pressure. To simulate the gravity loads of the reinforcement at different depths in practical engineering, a series of normal static loads were defined, including $60 \mathrm{kPa}, 80 \mathrm{kPa}, 100 \mathrm{kPa}, 120 \mathrm{kPa}, 200 \mathrm{kPa}$, and $300 \mathrm{kPa}$. In addition to static loads, the GRS structures are also subjected to dynamic loads such as earthquakes and traffic loads. To simulate the dynamic loads of the structures at different road conditions, a series of normal dynamic loads were defined, including frequency of $2 \mathrm{~Hz}, 4 \mathrm{~Hz}$, and $6 \mathrm{~Hz}$ and amplitude of $20 \mathrm{kPa}, 40 \mathrm{kPa}$, and $60 \mathrm{kPa}$. The loading curve and the magnitude of normal static loads and
TABle 2: Physical properties of coarse sand used in the study.

\begin{tabular}{lc}
\hline Parameter & Value \\
\hline Effective size, $D_{10}(\mathrm{~mm})$ & 0.16 \\
$D_{30}(\mathrm{~mm})$ & 0.49 \\
$D_{60}(\mathrm{~mm})$ & 1.1 \\
Average particle size, $D_{50}(\mathrm{~mm})$ & 0.79 \\
Particle diameter corresponding to $85 \%$ finer, $D_{85}(\mathrm{~mm})$ & 2.1 \\
Maximum particle size, $D_{\max }(\mathrm{mm})$ & 10 \\
Coefficient of uniformity, $C \mathrm{u}$ & 6.88 \\
Coefficient of curvature, $C \mathrm{c}$ & 1.36 \\
Specific gravity, Gs & 2.65 \\
Maximum dry unit weight, $\gamma_{\mathrm{dmax}}\left(\mathrm{kN} / \mathrm{m}^{3}\right)$ & 1.83 \\
Minimum dry unit weight, $\gamma_{\mathrm{dmin}}\left(\mathrm{kN} / \mathrm{m}^{3}\right)$ & 1.42 \\
Internal friction angle, $\varphi\left({ }^{\circ}\right)$, at $D_{\mathrm{r}}$ of $45 \%$ & 26.5 \\
\hline
\end{tabular}

TABLE 3: The engineering properties of the geogrid used in the tests (manufacturer's data).

\begin{tabular}{lc}
\hline Description & Value \\
\hline Type of geogrid & Stretched plastic \\
Material & High-density polyethylene \\
Mass per unit area $\left(\mathrm{kg} / \mathrm{m}^{2}\right)$ & 0.41 \\
Tensile strength $(\mathrm{kN} / \mathrm{m})$ & 95.3 \\
Tensile strength at $2 \%$ strain $(\mathrm{kN} / \mathrm{m})$ & 31.2 \\
Tensile strength at $5 \%$ strain $(\mathrm{kN} / \mathrm{m})$ & 58.2 \\
Elongation at failure $(\%)$ & 9.6 \\
\hline
\end{tabular}

dynamic loads are presented in Figure 4 and Table 4, respectively. Chen and $\mathrm{Su}[40]$ simulated the traffic loads with the sine wave and studied the dynamic response of subgrade by finite element software ABAQUS. Tian and Chu [41] analysed the load characteristics of traffic load and concluded that the sine wave was a reasonable way to simulate traffic load. Yu et al. [42] analysed the deformation characteristics and stability of widened embankment under two conditions with or without reinforcement by using sine wave to simulate traffic load. Hence, in this paper, the sine wave was used to simulate the dynamic loading. In addition, previous tests indicated that the pullout rate had a significant 


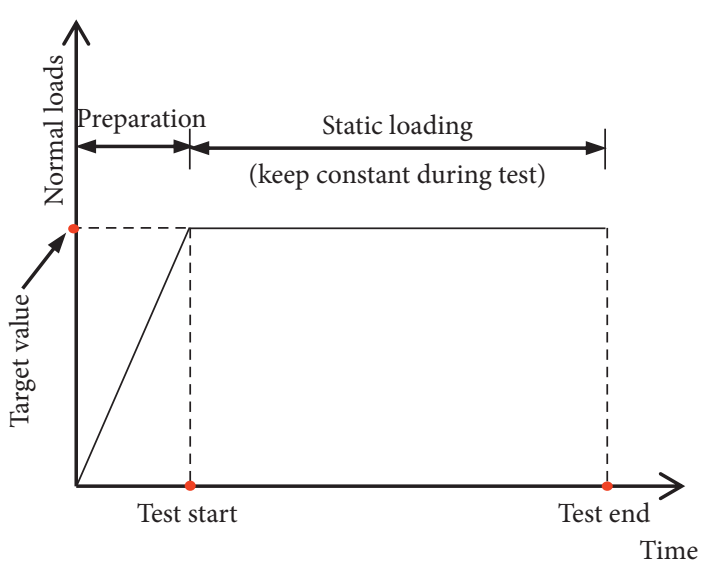

(a)

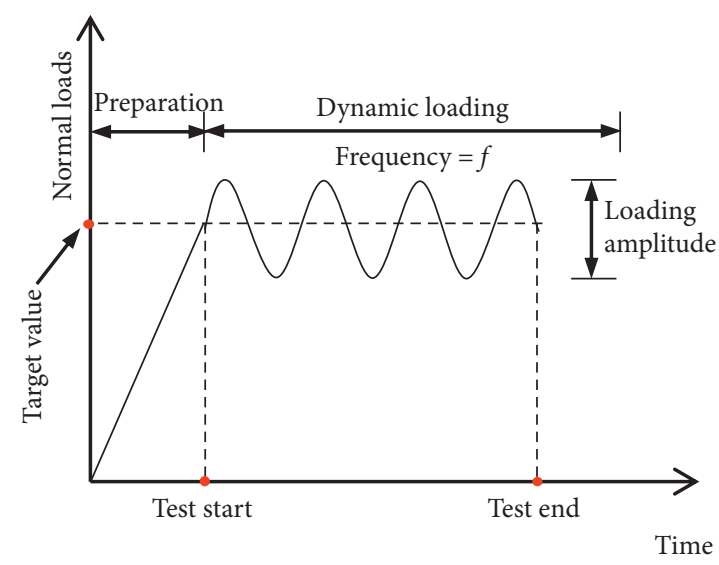

(b)

FIgure 4: The experimental loading process curve under different loading conditions: (a) static loads; (b) dynamic loads.

TABLE 4: Experimental programs of static and dynamic loading.

\begin{tabular}{|c|c|c|c|c|}
\hline Loading conditions & Magnitude of normal loading $(\mathrm{kPa})$ & Amplitude $(\mathrm{kPa})$ & Frequency $(\mathrm{Hz})$ & Pullout rate $(\mathrm{mm} / \mathrm{min})$ \\
\hline \multirow[t]{5}{*}{ Static } & $60,70,80,100,120,200,300$ & - & - & \\
\hline & & & 2 & \\
\hline & $60 \sim 80$ & 20 & 4 & \\
\hline & & & 6 & \\
\hline & & & 2 & \\
\hline \multirow[t]{5}{*}{ Dynamic } & $60 \sim 100$ & 40 & 4 & 2.0 \\
\hline & & & 6 & \\
\hline & & & 2 & \\
\hline & $60 \sim 120$ & 60 & 4 & \\
\hline & & & 6 & \\
\hline
\end{tabular}

influence on the experimental results. Therefore, the pullout rate used in the tests was kept constant at $2.0 \mathrm{~mm}$ per minute to minimize the effect of the pullout rate on the tests.

It can be seen from Figure 4 that the loading process is mainly composed of two stages. Stage one is the pullout preparation stage. At this stage, the horizontal control system is in a relaxed state, and the normal loading system will quickly reach the target value of the vertical load according to the experimental programs. Stage two is the pullout test. At this stage, the normal loading system can apply and maintain constant uniform normal loads on the infill material throughout testing, and the horizontal control system pulls the geogrid at a constant rate of $2.0 \mathrm{~mm} / \mathrm{min}$. It should be noted that the setting of the normal load time in the software operating system needs to be longer, because this time is counted from the experimental preparation stage, and the end time of the experiment is unknown. In this experiment, the pullout displacement is $100 \mathrm{~mm}$ and the pullout rate is $2.0 \mathrm{~mm} / \mathrm{min}$. The test takes about 50 minutes. However, the time required for the normal load to go from 0 to the target load in the experimental preparation stage, as well as the unforeseen conditions in the pullout test, also needs to be considered. Therefore, the normal static loading time of this experiment is set to $70 \mathrm{~min}$. As shown in Figure 4, unlike the static load, the dynamic load needs to input the frequency and amplitude in the second stage when the normal load reaches the target value. The sine wave was adopted to this test. Additionally, it is worth mentioning that, in Table 4, the aim of the selection of the normal static load of $70 \mathrm{kPa}$ is used to compare the differences in the mechanical behavior of the soil-geogrid interface under static and dynamic loading.

3.4. Experimental Procedures. The test procedures in this study are mainly comprised of three components: starting equipment, test preparation, and test. The experimental procedures are shown in Figure 5

It was worth mentioning that some details need to be paid attention to in the process of the test. Firstly, in the procedures of starting equipment, it is necessary to lubricate the sidewall of the pullout box by lubricant to minimize the effect of boundary on the test. Then, the height between the bottom of the box and the slot was $25 \mathrm{~cm}$. In the process of the backfilling, the infill materials should be backfilled in 5 layers and compacted. Next, before laying the geogrid, the surface of the infill materials needed to be shaved. In addition, the geogrid in the test box should be parallel to the two sidewalls of the test box and the distance should be symmetrical and equal to minimize the friction of the sidewall. Meanwhile, the laid geogrid should be prefixed by the clamp to avoid changing the position of the geogrid 

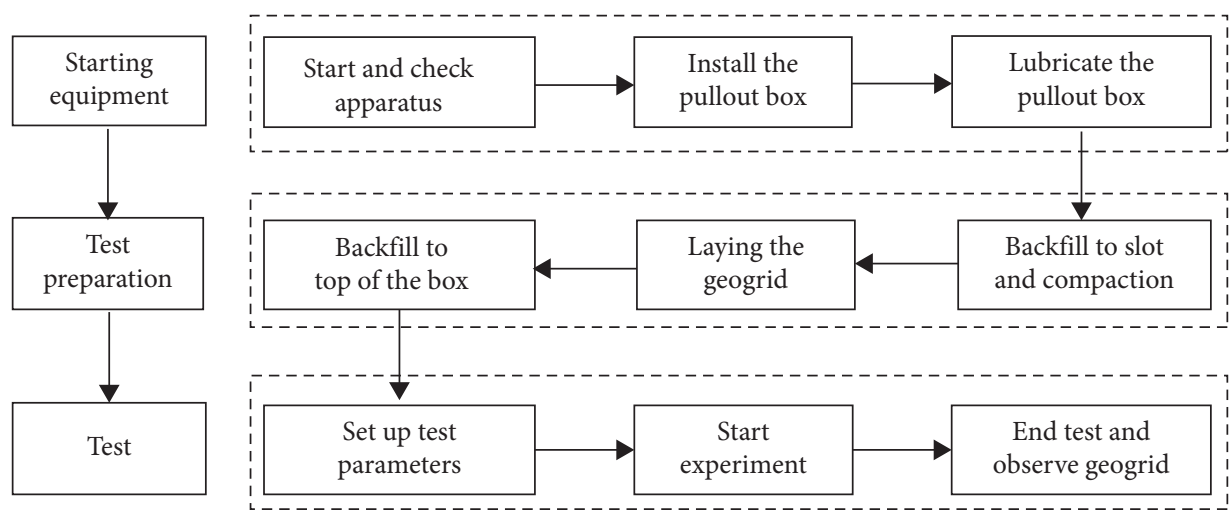

FIGURE 5: The test procedures in this study.

when the upper infill materials were backfilling. When the upper infill materials were backfilled to the top of the test box, the clamp should be loosened to release the prestress generated by the geogrid in the clamp in the process of backfilling, and then the geogrid reinforcement should be fixed again. Lastly, the pullout tests were conducted according to the experimental programs in Section 3.3.

\section{Results and Discussion}

This section presents a summary of the results and analyses of laboratory pullout tests conducted on HDPE uniaxial geogrid reinforced coarse sand subjected to static and dynamic loading by using the newly developed pullout apparatus. Firstly, the influence of the front displacement (FD) and the back displacement (BD) on the results of the pullout test was discussed. Then, the effects of the normal static and dynamic loads on the pullout resistance of the geogrid were discussed, respectively. Additionally, the variation laws of the interface shear strength parameters, including the apparent cohesion force and the apparent friction angle, with the static and dynamic load were also analysed. Finally, the similarities between the static loading and dynamic loading on the mechanical behavior of the soil-geogrid interface were analysed by comparing the results such as the pullout curve and pullout resistance.

4.1. Comparison of Front Displacement and Back Displacement. Figure 6 shows that the pullout resistance versus displacement that contains the front displacement (FD) and back displacement (BD) under the same normal static loading $(\sigma=80 \mathrm{kPa})$ was obtained from front sensors and back sensors, respectively.

It can be seen from Figure 6 that the curves of the FD and $\mathrm{BD}$ have both similarities and differences. The similarities were that the curve trends of the FD and the $\mathrm{BD}$ are the same, both of which showed that as the pullout displacement increases, the required pullout resistance gradually increases. It should be noted that the relationship between the displacement and pullout resistance was not directly proportional, because the geogrid was not an elastic material but an elastoplastic material. The differences were that the FD monitored by the displacement gauge installed at the clamp occurred at the moment when the pullout test was started, but the $\mathrm{BD}$ occurred only a period of time after the test started. The biggest reason for the difference between FD and BD was that the geogrid between the clamp and the front slot of the test box lacked lateral confinement generated from soil mass. Then, with the increase of pullout force provided by the horizontal control system, the load was transmitted along the longitudinal rib of geogrid and then the $\mathrm{BD}$ monitored by the additional displacement meter occurred when subjected to pullout force. The experimental results indicated that FD was mainly comprised of two parts: the tensile deformation of geogrid reinforcement between the clamp and the front slot of the test box, namely in the air, and the relative displacement between soil and geogrid in the box during the pullout tests. However, the back displacement contains only the relative displacement of soil and geogrid.

From the above analysis, it is determined that the back displacement can better reflect the relative horizontal displacement of the interface between soil and geogrid reinforcement as compared to the front displacement. Thus, the following results should be presented in terms of pullout resistance versus back displacement, rather than front displacement.

4.2. Effect of Static Loading on the Pullout Resistance. The plot of pullout resistance versus back displacement under six normal static loads, namely, $60 \mathrm{kPa}, 80 \mathrm{kPa}, 100 \mathrm{kPa}$, $120 \mathrm{kPa}, 200 \mathrm{kPa}$, and $300 \mathrm{kPa}$, is shown in Figure 7. It can be seen from Figure 7 that the tendency of the curve obtained from the laboratory pullout tests has similar characteristics, which showed that the pullout resistance increased and displacement decreased with an increase in the normal loading varying from $60 \mathrm{kPa}$ to $200 \mathrm{kPa}$, which was consistent with the conclusion obtained by Altay et al. [30], Wang et al. [43], and Yi et al. [44] through pullout tests. Meanwhile, the above conclusions also verified the reliability of the newly developed pullout apparatus. However, the geogrid suddenly broke in the 


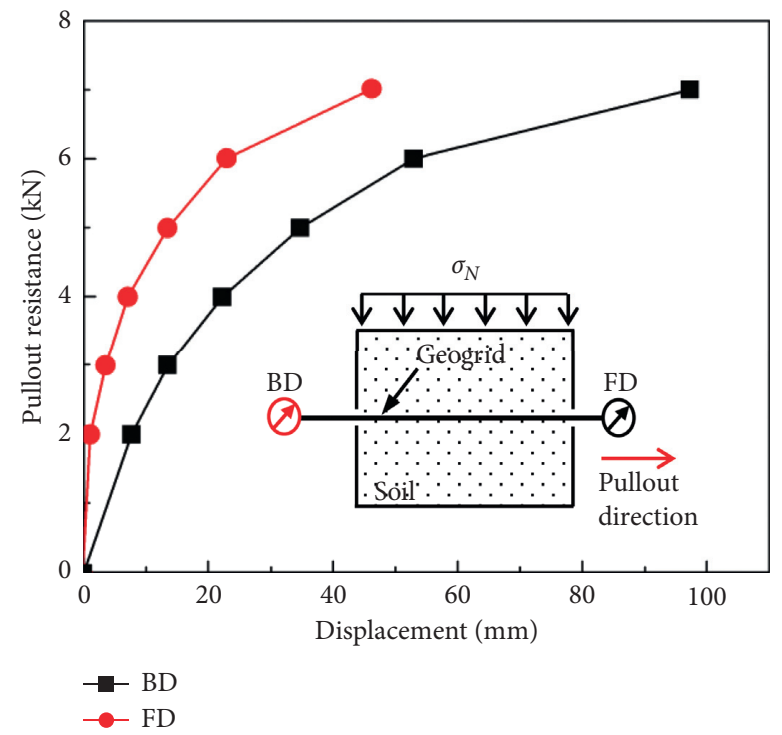

FIgure 6: Comparison of FD and BD under $\sigma=80 \mathrm{kPa}$.

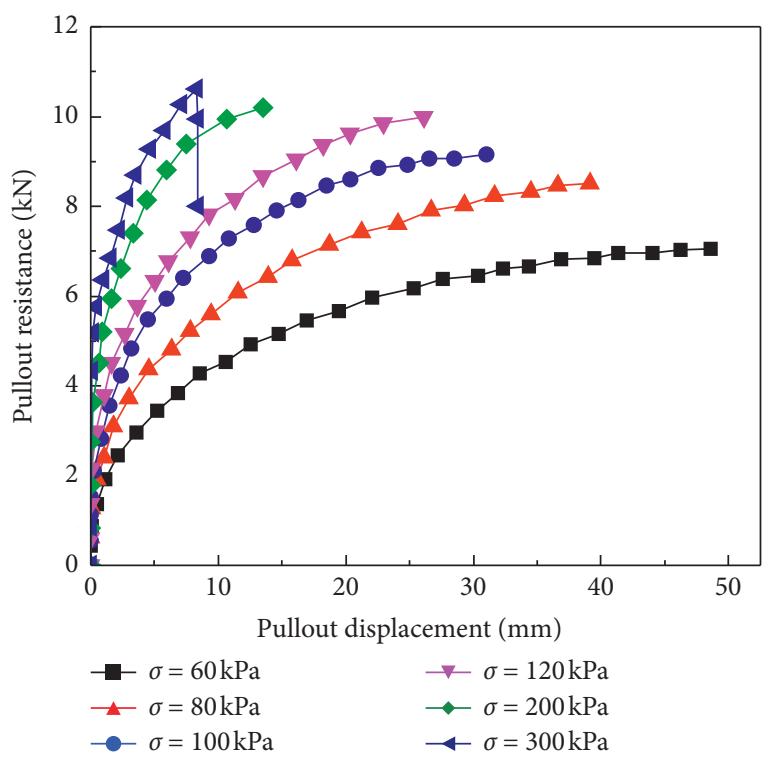

Figure 7: Pullout resistance-displacement under different normal static loads.

process of the pullout tests when subjected to normal stress $\sigma=300 \mathrm{kPa}$ and then the pullout resistance dropped sharply. It was found that the magnitude of the normal static loading directly affected the pullout resistance.

To further investigate the effect of normal static loading on the pullout resistance of geogrid, the pullout resistance corresponding to the normal loads is presented in Figure 8. It should be noted that the pullout resistance corresponding to the normal loads of $300 \mathrm{kPa}$ cannot be used, because the geogrid reinforcement was broken rather than pulled out during the test. Thus, it is necessary to discard this group of the experimental data obtained from the pullout test under $\sigma=300 \mathrm{kPa}$.

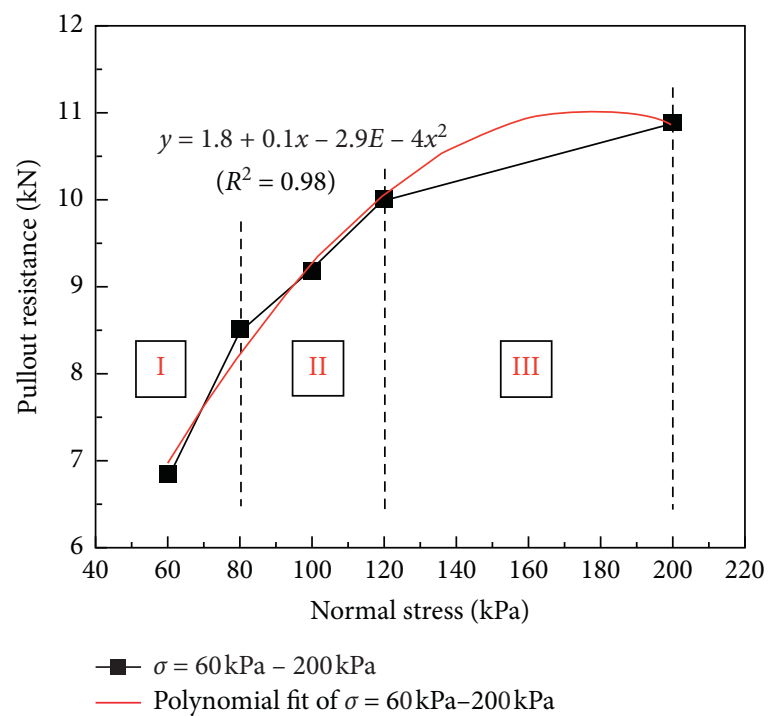

FIGURE 8: Global polynomial fitting of normal loads versus pullout resistance under $\sigma=60 \mathrm{kPa}-200 \mathrm{kPa}$.

It can be seen from Figure 8 that the pullout resistance increases with the increase of the normal loads from $60 \mathrm{kPa}$ to $200 \mathrm{kPa}$, but the pullout resistance presents different growth modes. According to the increase of the pullout resistance, it can be roughly divided into three regions, which are region I, region II, and region III, as shown in Figure 8. Region I was the normal load increasing from $60 \mathrm{kPa}$ to $80 \mathrm{kPa}$, and the pullout resistance increased by $1.65 \mathrm{kN}$. Region II was the normal load increasing from $80 \mathrm{kPa}$ to $120 \mathrm{kPa}$, and the increase in pullout resistance was about $0.7 \mathrm{kN}$, which was a decrease of $59.6 \%$ compared with region I. Region III was the normal load increasing from $120 \mathrm{kPa}$ to $200 \mathrm{kPa}$, and the increase in pullout resistance was only $0.22 \mathrm{kN}$, which was a decrease of $68.6 \%$ compared with 
region II. Therefore, it can be seen that the change of the normal static load has a great influence on the pullout resistance. Specifically, the influence of normal loading on pullout resistance was gradually weakened.

Considering that there are three growth modes of pullout resistance with the increase of normal loads, an approach of global polynomial fitting for the whole test procedure was adopted to analyse the relationship between the pullout resistance of the geogrid used in this study and the normal static load. As can be seen from Figure 8, when the normal load was small, the pullout resistance increased as the normal load increased, but when the normal load was greater than a certain value, the pullout resistance decreased instead. In addition, when a certain normal load was reached, such as $\sigma=300 \mathrm{kPa}$, the pullout resistance of the interface between the soil and reinforcement was greater than the tensile strength of the geogrid, and then the geogrid would break. This certain value of the normal load is called critical normal load, and the corresponding pullout resistance is called the maximum pullout resistance of geogrid used in this test. Under the critical normal load, the strength of both the infill material and the geogrid can be fully exhibited, so the pullout resistance can reach the maximum. According to the polynomial fitting equation, the critical normal load of the geogrid used in this study is $176 \mathrm{kPa}$, and the corresponding pullout resistance is $10.42 \mathrm{kN}$. The determination of the critical normal load not only helps to provide a reference for the selection of reinforcement placed at different depths but also is of benefit to make full use of the material and then reflects significant economic advantages of reinforced soil structures. Hence, it is necessary to determine the critical normal load corresponding to the maximum pullout resistance by conducting a series of laboratory tests in the design of the geogrid reinforced soil structures, such as retaining walls and slopes, especially for steep slopes.

According to the calculation formula of the shear stress, the shear stress of the soil-geogrid interface under different normal static loads was calculated. The plot of the relationship between the shear stress and the different normal loads is shown in Figure 9. The interface shear strength parameters that contain the apparent cohesion force and the apparent friction angle were obtained from piecewise linear fitting according to the three areas mentioned above. The piecewise linear fitting equation is also shown in Figure 9. To further analyse the influence of the magnitude of the normal static load on the shear strength parameters, the variation laws of the shear strength parameters, including the apparent cohesion force and the apparent friction angle, with three regions are presented in Figure 10.

It can be seen from Figure 10 that the apparent cohesion force increases with an increase of the normal static loading, while the apparent friction angle decreases instead. When the normal loading increases from region I to region II, the apparent cohesion force increases from $5.33 \mathrm{kPa}$ to $15.27 \mathrm{kPa}$, a significant increase of $186.5 \%$, and the apparent friction angle decreases from $13^{\circ}$ to $6.3^{\circ}$, a decrease of $51.5 \%$. When the normal load increases from region II to region III, the apparent cohesion increases from $15.27 \mathrm{kPa}$ to $24.16 \mathrm{kPa}$, an increase of $58.2 \%$, and the apparent friction angle

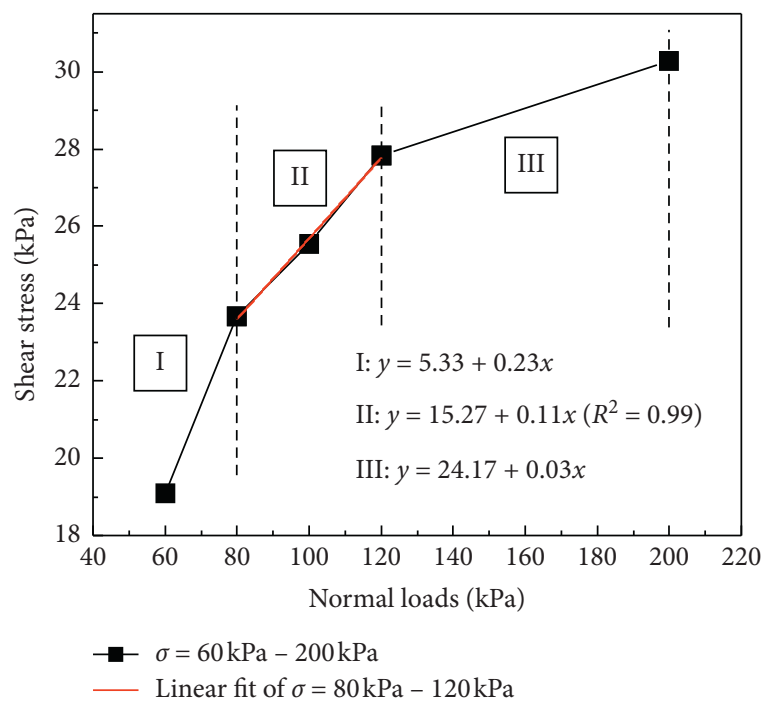

FIgURE 9: The relationship and fitting between the shear stress and the different normal loads.

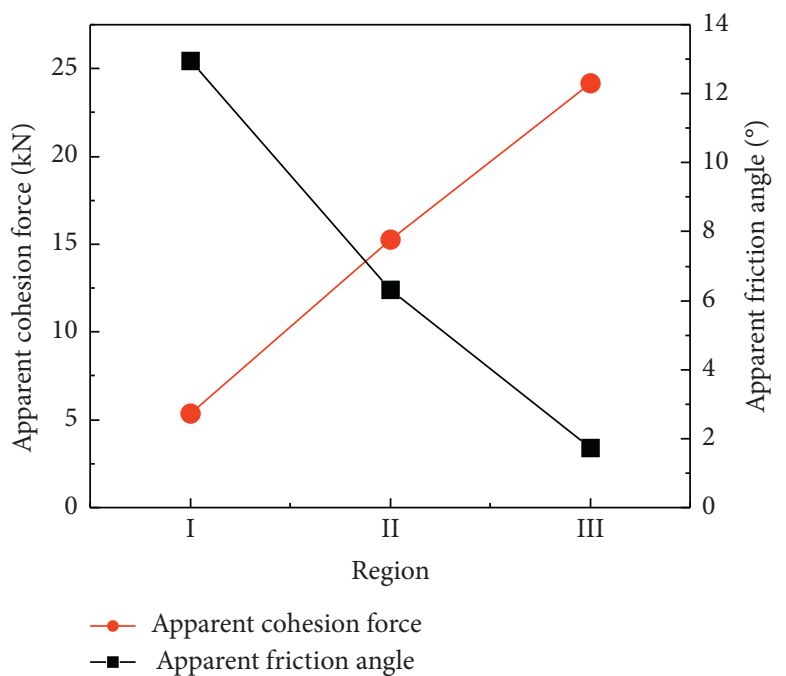

FIGURE 10: The variation laws of the shear strength parameters with three regions.

decreases from $6.3^{\circ}$ to $1.8^{\circ}$, a decrease of $71.4 \%$. It can be seen that the magnitude of the normal static loading has a significant impact on the shear strength parameters of the soilgeogrid interface. However, with the normal load increases, the magnitude of the increase in apparent cohesion decreases and the magnitude of the decrease in apparent friction angle increases. The reason is that as the normal load increases, the geogrid and coarse sand increase in density, especially near the transverse ribs at the interface. This helps the passive bearing capacity of the geogrid to gradually develop, so the apparent cohesive force is significantly increased. However, when the normal load continues to increase, the particles may break and then cause the particle size distribution to change. The particle size of the infill material is reduced, which results in an increase in the decrease in the apparent friction angle, and, at the same time, 


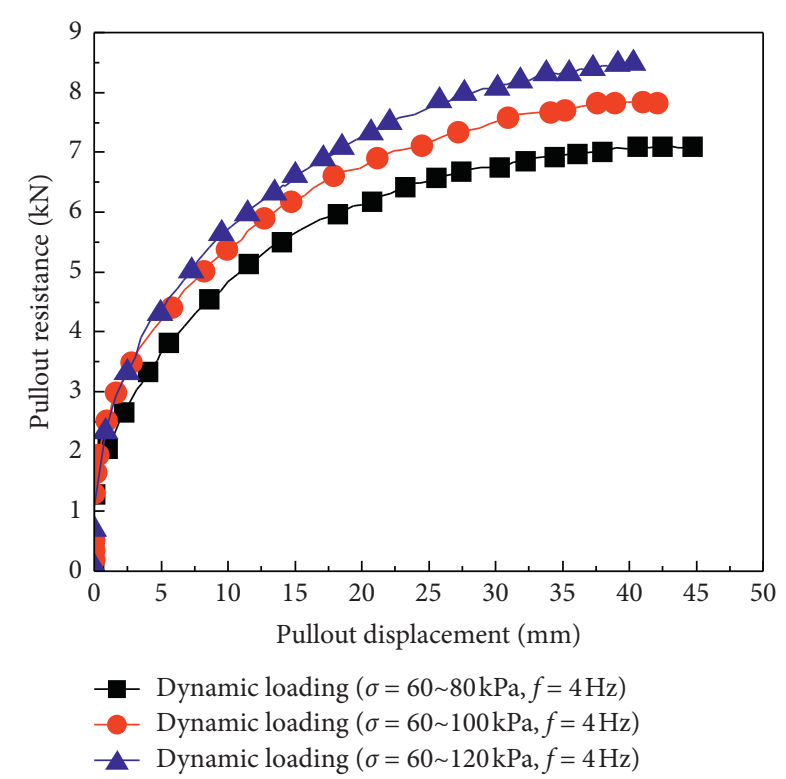

Figure 11: The curve of the pullout displacement versus pullout resistance under dynamic loading.

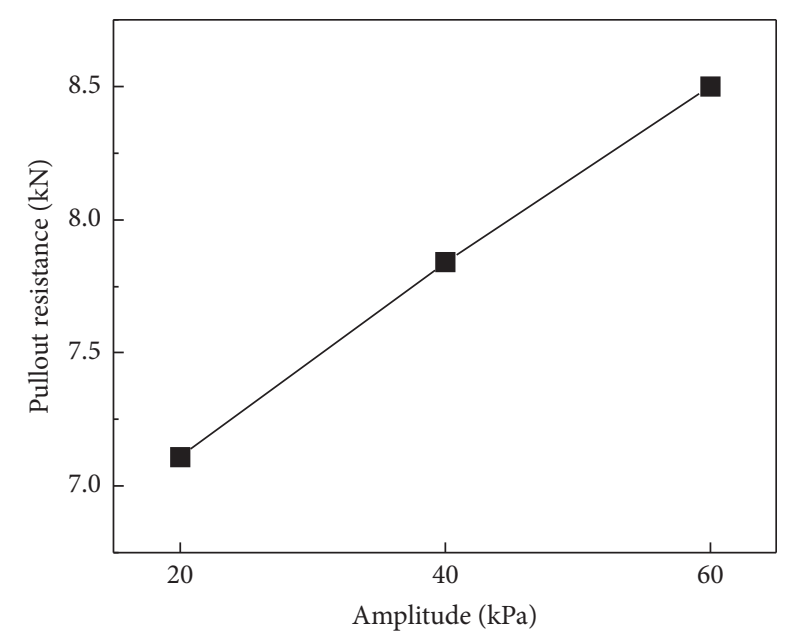

FIgURE 12: The curve of the amplitude versus pullout resistance.

the component of the pullout resistance provided by the transverse ribs is reduced.

\subsection{Effect of Dynamic Loading on the Pullout Resistance.} Figure 11 shows the plot of the pullout displacement versus pullout resistance of geogrid reinforced coarse sand subjected to dynamic loading with the same frequency and the different amplitude of $20 \mathrm{kPa}, 40 \mathrm{kPa}$, and $60 \mathrm{kPa}$. It can be seen from Figure 11 that the pullout resistance increases with an increase in the magnitude of the amplitude under the same frequency, which was consistent with the conclusions obtained by Cardile et al. [37] and Xu and Shi [45]. Additionally, the curve trend of pullout displacement versus pullout resistance under dynamic load is similar to that under static load, which provides the possibility for the equivalent of the dynamic load.
To quantitatively analyse the effect of the amplitude on the pullout resistance of geogrid under dynamic loading, the pullout resistance corresponding to the amplitude is presented in Figure 12. It can be seen from Figure 12 that the pullout resistance was directly influenced by the amplitude. The pullout resistance increases linearly with the increase of the amplitude of the dynamic load, and the increment is about $0.6 \mathrm{kN}$. The experimental results revealed that the dynamic loading with a larger amplitude has a greater influence on the pullout resistance of the soil-geogrid interface under the same frequency.

The plot of the geogrid reinforced coarse sand subjected to dynamic loading with the same amplitude $(20 \mathrm{kPa}$ and $40 \mathrm{kPa})$ and the different frequency $(2,4$, and $6 \mathrm{~Hz}$ ) and frequency versus pullout resistance is shown in Figure 13. Additionally, the relationship of the pullout behavior of the geogrid subjected to static and dynamic loading was also discussed, because the curve trend of pullout displacement and pullout resistance under dynamic load is similar to that of the static load. To compare and analyse the influence of normal static load $(60 \mathrm{kPa}$ and $80 \mathrm{kPa})$ and dynamic load $(60 \sim 80 \mathrm{kPa})$ on the friction characteristics of the soil-geogrid interface, the pullout test was also conducted under static load of $70 \mathrm{kPa}$. It is worth mentioning that $70 \mathrm{kPa}$ was the balance position of the lower limit value $(60 \mathrm{kPa})$ and upper limit value $(80 \mathrm{kPa})$ of normal dynamic load.

It can be seen from Figures 13(a) and 13(b) that both the pullout resistance increased with an increase in the frequency under the same amplitude. By placing the pullout curves of static and dynamic loading together, some rules can be observed, which can provide ideas for simplifying the study of dynamic loads. The pullout curve under dynamic loading changed within the upper and lower limits of the static loading. Furthermore, the pullout curves of the dynamic loading at different frequencies do not exceed the two pullout curves corresponding to the upper and lower limits of the static loading, but the degree of deviation is different. Additionally, the pullout resistance increased with an increase in the frequency under the same amplitude and gradually approached the pullout resistance under the normal static load corresponding to the balance position of dynamic loading. The test results indicated that the dynamic loading action with a smaller frequency is close to the static load action corresponding to the lower limit value of the dynamic load. At the same time, with an increase in the frequency, the effect of dynamic loading on the interface of soil and geogrid can be gradually equivalent to that of static loading corresponding to the balance position of dynamic load.

To further investigate the effect of frequency on the pullout resistance, the plot of the frequency versus the pullout resistance was shown in Figure 14. As shown in Figure 14, the pullout resistance increases linearly with the increase of the frequency of the dynamic load, and the increment is $0.3 \mathrm{kN}$ and $0.5 \mathrm{kN}$, respectively. The test results indicated that the dynamic loading with larger frequency has a greater influence on the pullout resistance of the interface between soil and geogrid under the same amplitude. 


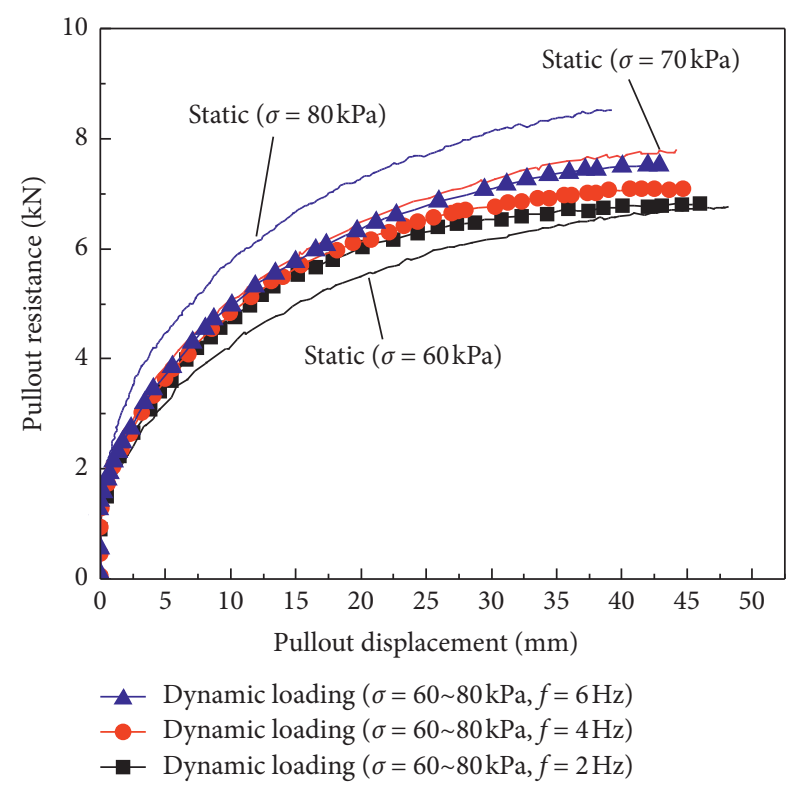

(a)

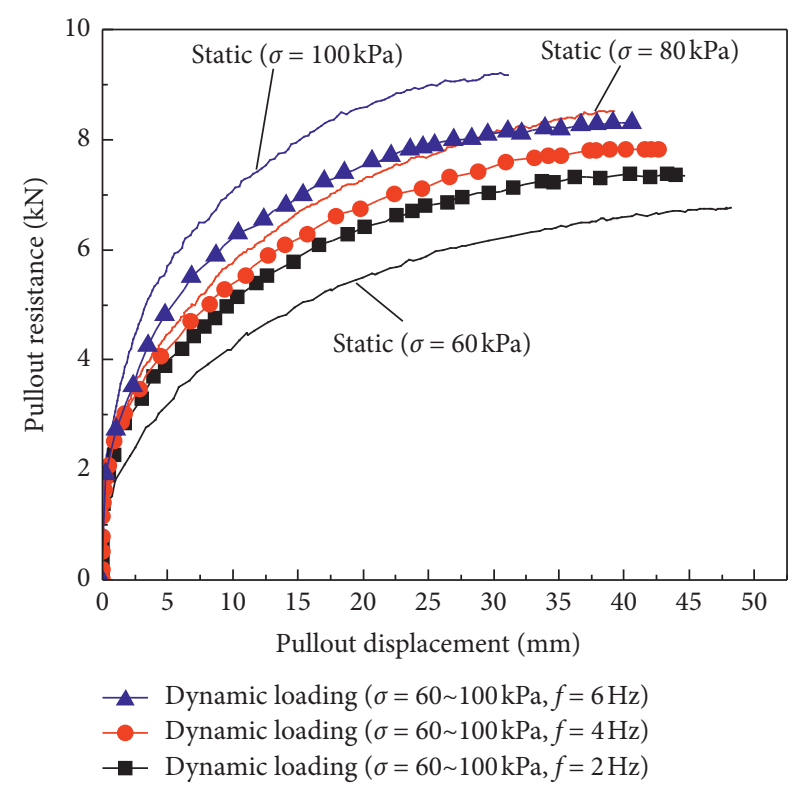

(b)

FIGURE 13: Effect of frequency and loading condition on the pullout resistance: (a) $\sigma=60 \sim 80 \mathrm{kPa}$; (b) $\sigma=60 \sim 100 \mathrm{kPa}$.

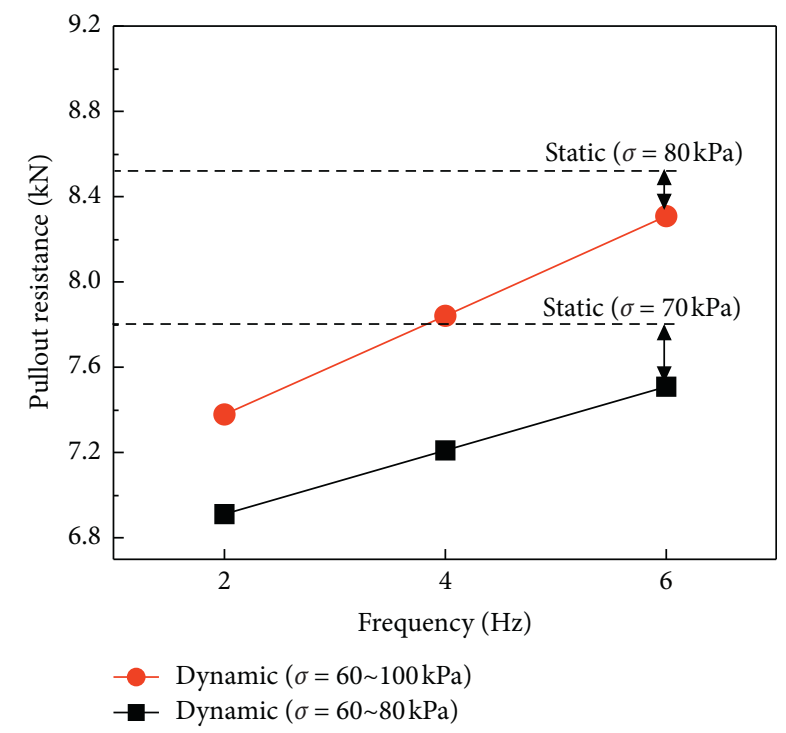

FIGURE 14: The relationship of the frequency and pullout resistance under different amplitude.

Meanwhile, the dynamic loading with a larger amplitude has a greater influence on the pullout resistance was also validated. In addition, the difference between the dynamic loading $(\sigma=60 \sim 80 \mathrm{kPa} ; \sigma=60 \sim 100 \mathrm{kPa})$ with larger frequency $(f=6 \mathrm{~Hz})$ and the static loading $(\sigma=70 \mathrm{kPa}$; $\sigma=80 \mathrm{kPa}$ ) which was the balance position of dynamic loading was $0.31 \mathrm{kN}$ and $0.20 \mathrm{kN}$, respectively. Hence, the difference between the dynamic loading and the static loading corresponding to the balance position of dynamic loading decreased with the increase of the frequency and amplitude. Through the above analysis, the idea of simplifying the research of dynamic load can be obtained, thus improving understanding of the pullout behavior of the geogrid reinforcement subjected to static and dynamic loading.

The reason is that some of the larger particles, especially near the transverse ribs at the interface, were crushed under dynamic loading of different frequencies due to the normal dynamic load from the lower limit value to the upper limit value in a short time, thus reducing the passive bearing capacity of the transverse rib on the coarse sand. Hence, the pullout curve of dynamic loading is close to the pullout curve of static load corresponding to the lower limit of dynamic load amplitude. At the same time, with the increase of the frequency, the density of the infill material in the test box increases, and the influence of frequency in dynamic loading is gradually weakened. Specifically, the effect of dynamic loading on the soil-geogrid interface gradually tends to that of static loading corresponding to the balance position of the dynamic loading.

\section{Conclusions}

This paper presents a series of experimental investigations on HDPE uniaxial geogrid under static and dynamic loading by using the new pullout apparatus. The variation laws of the friction characteristics and the shear strength parameters of the soil-geogrid interface with the magnitude of normal static loading, frequency and amplitude of dynamic loading, and the idea of simplifying research on dynamic loading were analysed by comparing the experimental results obtained from laboratory pullout tests. The following conclusions were obtained.

The pullout resistance presented three growth modes with the increase of the normal loads, while the influence of normal loading on pullout resistance was gradually 
weakened. A critical normal load was developed to provide a reference for the selection of reinforcement placed at different depths, benefiting to make full use of the material. The apparent cohesion force increases with an increase of the normal static loading, while the apparent friction angle decreases instead.

The normal static loading, the amplitude, and frequency of normal dynamic load had significant influences on the friction characteristics of soil-geogrid interface under $60-80 \mathrm{kPa}$, and the increment of the pullout resistance was $1.65 \mathrm{kN}, 0.6 \mathrm{kN}$, and $0.3 \mathrm{kN}$, respectively. Hence, the influence of normal static loading is greater than that of the amplitude and frequency of the normal dynamic loading.

The effect of dynamic loading on the soil-geogrid interface tends to the action of the static loading corresponding to the balance position of dynamic loading with the increase of frequency of dynamic loading. This study is helpful to simplify the study of the stress state of the reinforcement under dynamic loading in the design and stability analysis of the reinforced soil structure, avoiding the failure of the structure.

In this paper, the sine wave was used to simulate the dynamic load, which had some limitations in reflecting the traffic load. Therefore, we will study the influence of complex dynamic loads on the soil-geogrid interface in the follow-up work.

\section{Data Availability}

The data used to support the findings of this study are available from the corresponding author upon request.

\section{Conflicts of Interest}

The authors declare that there are no conflicts of interest regarding the publication of this paper.

\section{Acknowledgments}

This research was funded by the National Natural Science Foundation of China (NSFC) (Grants nos. 51709175 and 51378322), the Funded Project for Innovative Graduates in Hebei, China (Grant no. CXZZBS2020145), Scientific Research Foundation for the Returned Overseas Scholars of Hebei Province (Grant no. CL201722), Natural Science Foundation of Hebei Province (Grant no. E2018210097), and Science and Technology Research Projects of Universities in Hebei Province (Grant no. QN2018255).

\section{References}

[1] X. Wang, L. Ding, W. Gao et al., "Research on subgrade differential settlement control standard and treatment technology based on driving comfort," Advances in Materials Science and Engineering, vol. 2020, Article ID 8956458, 14 pages, 2020.

[2] P. E. Burak and A. M. Vefa, "Comparison of effects of using geosynthetics and lime stabilization to increase bearing capacity of unpaved road subgrade," Advances in Materials
Science and Engineering, vol. 2016, Article ID 7129356, 8 pages, 2016.

[3] J. Zhang, S. W. Liu, and H. F. Pu, "Evaluation of an improved technique for geosynthetic-reinforced and pile-supported embankment," Advances in Materials Science and Engineering, vol. 2015, Article ID 612760, 9 pages, 2015.

[4] L. J. Wu, "Performance of geosynthetic-reinforced and cement-fly ash-gravel pile-supported embankments over completely decomposed granite soil: a case study," Advances in Materials Science and Engineering, vol. 2018, Article ID 2659628, 11 pages, 2018.

[5] L. H. Li, J. C. Yang, H. L. Xiao et al., "“Behavior of tiregeogrid-reinforced retaining wall system under dynamic vehicle load," International Journal of Geomechanics, vol. 20, no. 4, pp. 1-12, 2020.

[6] J. Han, Y. Jiang, and C. Xu, "Recent advances in geosyntheticreinforced retaining walls for highway applications," Frontiers of Structural and Civil Engineering, vol. 12, no. 2, pp. 239-247, 2018.

[7] X. L. Jia, J. L. Xu, and Y. H. Sun, "Deformation analysis of reinforced retaining wall using separate finite element," Discrete Dynamics in Nature and Society, vol. 2018, Article ID 6946492, 9 pages, 2018.

[8] R. Zhang, M. X. Long, and J. L. Zheng, "Comparison of environmental impacts of two alternative stabilization techniques on expansive soil slopes," Advances in Civil Engineering, vol. 2019, Article ID 9454929, 13 pages, 2019.

[9] Y. Kurakami and Y. Nihei, "Resistance of laminar drain reinforcement levee against overflow erosion," Water, vol. 11, no. 9, pp. 1768-1782, 2019.

[10] A. Kiersnowska, E. Koda, W. Fabianowski, and J. Kawalec, "Effect of the impact of chemical and environmental factors on the durability of the high density polyethylene (HDPE) geogrid in a sanitary landfillfill," Applied Sciences, vol. 7, no. 1, pp. 22-36, 2016.

[11] S. Xu, C. Li, J. Liu et al., "Deformation and hydraulic conductivity of compacted clay under waste differential settlement," Processes, vol. 6, no. 8, pp. 123-133, 2018.

[12] K. C. Foye, "Use of reclaimed asphalt pavement in conjunction with ground improvement: a case history," Advances in Civil Engineering, vol. 2011, Article ID 808561, 7 pages, 2011.

[13] J. Xiao, H. P. Yang, J. H. Zhang et al., "Surficial failure of expansive soil cutting slope and its flexible support treatment technology," Advances in Civil Engineering, vol. 2018, Article ID 1609608, 13 pages, 2018.

[14] Y. J. Kim, A. R. Kotwal, B. Y. Cho et al., "Geosynthetic reinforced steep slopes: current technology in the United States," Applied Sciences-Basel, vol. 9, no. 1, pp. 2008-2031, 2019.

[15] Z. Martin, “Application of geogrid reinforced constructions: history, recent and future developments," Procedia Engineering, vol. 172, pp. 42-51, 2017.

[16] C.-N. Liu, K.-H. Yang, Y.-H. Ho, and C.-M. Chang, "Lessons learned from three failures on a high steep geogrid-reinforced slope," Geotextiles and Geomembranes, vol. 34, pp. 131-143, 2012.

[17] H. Xia, J. Zhang, J. Cai, H. Pan, and X. She, "Study on the bearing capacity and engineering performance of aeolian sand," Advances in Materials Science and Engineering, vol. 2020, Article ID 3426280, 11 pages, 2020.

[18] W. Zhang, D. Du, and X. H. Bai, "In situ testing of square footing resting on geobelt-reinforced gravel thin cushion on 
soft silt," Advances in Materials Science and Engineering, vol. 2018, Article ID 3563914, 12 pages, 2018.

[19] J. Q. Wang, L. L. Zhang, J. F. Xue et al., "Load-settlement response of shallow square footings on geogrid-reinforced sand under cyclic loading," Geotextiles and Geomembranes, vol. 46, pp. 319-326, 2018.

[20] G.-Q. Yang, H. Liu, Y.-T. Zhou, and B.-L. Xiong, "Postconstruction performance of a two-tiered geogrid reinforced soil wall backfilled with soil-rock mixture," Geotextiles and Geomembranes, vol. 42, no. 2, pp. 91-97, 2014.

[21] S. Balakrishnan and B. V. S. Viswanadham, "Performance evaluation of geogrid reinforced soil walls with marginal backfills through centrifuge model tests," Geotextiles and Geomembranes, vol. 44, no. 1, pp. 95-108, 2016.

[22] P. S. Prasad and G. V. Ramana, "Feasibility study of copper slag as a structural fill in reinforced soil structures," Geotextiles and Geomembranes, vol. 44, no. 4, pp. 623-640, 2016.

[23] P. S. Prasad and G. V. Ramana, "Imperial smelting furnace (zinc) slag as a structural fill in reinforced soil structures," Geotextiles and Geomembranes, vol. 44, no. 3, pp. 406-428, 2016.

[24] M. R. Abdi and M. A. Arjomand, "Pullout tests conducted on clay reinforced with geogrid encapsulated in thin layers of sand," Geotextiles and Geomembranes, vol. 29, no. 6, pp. 588-595, 2011.

[25] H. L. Wang, R. P. Chen, Q. W. Liu et al., "Soil-geogrid interaction at various influencing factors by pullout tests with applications of FBG sensors," Journal of Materials in Civil Engineering, vol. 31, no. 1, Article ID 04018342, 2019.

[26] M. R. Abdi and H. Mirzaeifar, "Experimental and PIV evaluation of grain size and distribution on soil-geogrid interactions in pullout test," Soils and Foundations, vol. 57, no. 6, pp. 1045-1058, 2017.

[27] X.-z. Cui, Y.-l. Wang, K.-w. Liu et al., “A simplified model for evaluating the hardening behaviour of sensor-enabled geobelts during pullout tests," Geotextiles and Geomembranes, vol. 47, no. 3, pp. 377-388, 2019.

[28] M. R. Abdi and A. R. Zandieh, "Experimental and numerical analysis of large scale pull out tests conducted on clays reinforced with geogrids encapsulated with coarse material," Geotextiles and Geomembranes, vol. 42, no. 5, pp. 494-504, 2014.

[29] F. M. Ezzein and R. J. Bathurst, "A new approach to evaluate soil-geosynthetic interaction using a novel pullout test apparatus and transparent granular soil," Geotextiles and Geomembranes, vol. 42, no. 3, pp. 246-255, 2014.

[30] G. Altay, C. Kayadelen, T. Taşkıran, and Y. Z. Kaya, "A laboratory study on pull-out resistance of geogrid in clay soil," Measurement, vol. 139, pp. 301-307, 2019.

[31] Z. Wang, F. Jacobs, and M. Ziegler, "Experimental and DEM investigation of geogrid-soil interaction under pullout loads," Geotextiles and Geomembranes, vol. 44, no. 3, pp. 230-246, 2016.

[32] X. Peng and J. G. Zornberg, "Evaluation of soil-geogrid interaction using transparent soil with laser illumination," Geosynthetics International, vol. 26, no. 2, pp. 206-221, 2019.

[33] G. Cardile, D. Gioffrè, N. Moraci, and L. S. Calvarano, "Modelling interference between the geogrid bearing members under pullout loading conditions," Geotextiles and Geomembranes, vol. 45, no. 3, pp. 169-177, 2017.

[34] P. Aali, D. Manoj, G. V. Ramana et al., "Measurement of role of transverse and longitudinal members on pullout resistance of PET geogrid," Measurement, vol. 148, Article ID 106944, 2019.
[35] L. H. Li, Y. J. Chen, Y. Liu et al., "Experimental investigations on the pull-out behavior of tire strips reinforced sands," Materials, vol. 10, no. 7, pp. 707-719, 2017.

[36] A. H. Abdel-Rahman and A. M. Ibbrahim, "Soil-geogrid behavior subjected to cyclic loading," Geo-frontiers: Advances in Geotechnical Engineering, pp. 3087-3096, 2011.

[37] G. Cardile, M. Pisano, and N. Moraci, "The influence of a cyclic loading history on soil-geogrid interaction under pullout condition," Geotextiles and Geomembranes, vol. 47, no. 4, pp. 552-565, 2019.

[38] Z. Liu, K. Y. Shi, and Y. Lei, "Model test on dynamic characteristics of geogrid reinforced earth retaining wall packet ecological bag under repeated loading," Journal of Vibration and Shock, vol. 34, no. 9, pp. 88-94, 2015.

[39] S. K. K. Hussaini, B. Indraratna, and J. S. Vinod, "Performance assessment of geogrid-reinforced railroad ballast during cyclic loading," Transportation Geotechnics, vol. 2, pp. 99-107, 2015.

[40] J. Chen and Y. H. Su, "Numerical simulation of dynamic performance of highway subgrade under traffic loads," Journal of Highway and Transportation Research and Development, vol. 25, no. 5, pp. 44-48, 2011.

[41] F. Tian and J. J. Chu, "Research on traffic load characteristics and simulation methods," Journal of Water Resources and Architectural Engineering, vol. 12, no. 4, pp. 66-71, 2014.

[42] H. Yu, J. J. Zheng, W. Z. Cao et al., "Dynamic characteristics analysis of widening embankments under asymmetric traffic loading," China Earthquake Engineering Journal, vol. 39, no. 6, pp. 1111-1117, 2018.

[43] J. Q. Wang, J. Zhou, Y. B. Deng et al., "Pull-out test analysis of sand and geosynthetics," Journal of Guangxi University (Natural Science Edition), vol. 36, no. 4, pp. 659-663, 2011.

[44] F. Yi, Y. N. Zhang, S. J. Wang et al., "Pull-out test and tensile of geogrids and tailings," Bulletin of the Chinese Ceramic Society, vol. 37, no. 6, pp. 1836-1840, 2018.

[45] C. Xu and Z. L. Shi, "Experiment of influence of cyclic load characteristics on shear properties of geogrid-soil interface," China Journal of Highway and Transport, vol. 24, no. 3, pp. 1-7, 2011. 